\title{
An Innovative Method for Installing a Separate Sewer System in Narrow Streets
}

\author{
Alaa Abbas, ${ }^{1}$ I. Carnacina, ${ }^{1}$ F. Ruddock, ${ }^{1}$ R. Alkhaddar, ${ }^{1}$ G. Rothwell ${ }^{1}$ and R. Andoh ${ }^{2}$ \\ ${ }^{1}$ Liverpool John Moores University, Liverpool, UK; ${ }^{2} A W D$ Consult Inc., Ellenwood, Georgia.
}

\begin{abstract}
Separate sewer systems are currently used in all new developments and are prevalent in comparison with combined sewer systems, the use of which is limited due to numerous environmental regulations. However, the narrow streets common in the United Kingdom, Europe, and other densely populated countries are usually occupied by complex networks of infrastructure services; consequently, finding space to install a traditional separate sewer system is challenging. This paper presents an original design for separate sewer systems that overcomes this challenge by combining the advantages of separate and combined sewerage systems into one sewer network. The proposed system includes a novel design for the access chamber shape that allows storm flows and foul flows to pass through it without mixing and allows one trench to accommodate both pipelines. Applying this system in a case study showed a reduction in construction costs of approximately $10 \%$ and a $16 \%$ reduction in the footprint; moreover, the construction time was decreased by $44 \%$, and the storage capacity and retention time were increased by $280 \%$ and $200 \%$, respectively.
\end{abstract}

\section{Introduction}

Traditionally, there are two types of drainage systems: the combined sewer system (CSS) and the separate sewer system (SSS). The CSS, which uses a single pipe to convey both sanitary sewage and stormwater, has been used effectively in the past because of its simplicity, and it was most effective when cities had a low population density. Approximately $70 \%$ of the sewer systems in the United Kingdom and in many European countries such as Germany, France and Belgium use CSSs (Butler and Davis 2011). A CSS is designed to release untreated overflows into watercourses through a combined sewer overflow (CSO) to keep the hydraulic load and dilution at manageable levels when the capacity of the sewer system is insufficient to carry the entire flow (both storm water and sewage) through a heavy rain event (Brombach et al. 2005). As an example, approximately $16 \mathrm{Mt}$ wastewater is discharged annually from overflows into the Lee River in the Stratford area of London (DEFRA 2012).

Unfortunately, the frequency and negative consequences of overflows from CSOs are likely to become exacerbated by the impacts of climate change (Astaraie-Imani et al. 2012). Since the middle of the last century, SSSs have been widely adopted in many countries to conform to new environmental regulations. An SSS uses two sets of pipelines: one to convey foul flow to a wastewater treatment plant (WWTP) and the other to convey stormwater to the nearest watercourse. An SSS is designed to address the harmful environmental impacts of CSSs and to prevent flooding by increasing the capability of the stormwater drainage system to separately convey to the nearest watercourse runoff caused by heavy rain.
Despite recent debate about the pollution load that can be carried in stormwater and discharged into watercourses (Ferreira et al. 2011; Ouyang et al. 2012), an SSS has certain disadvantages due to its construction cost and footprint. Installing the two sets of pipelines required for an SSS is difficult due to the limited amount of space beneath the narrow streets prevalent in cities throughout the United Kingdom and Europe and in cities throughout Eastern countries. These streets are normally occupied by complex networks of infrastructure services, such as potable water, electricity, communication and gas lines, so finding space in which to place two additional sets of pipelines constitutes a challenging task for both designers and water companies (Broere 2016).

Nevertheless, the new technologies available today for the design, manufacture, maintenance and inspection of sewer systems have encouraged designers to revisit traditional urban drainage management from an innovative perspective. The United States Environmental Protection Agency (USEPA) implemented a project that provided an overview of many recent works on sewer systems. Examples of innovative system designs identified in the USEPA study include the use of real-time control, vacuum sewerage technology, best management practices (BMPs) and retrofitting technologies such as sustainable drainage systems (SuDS). Wang et al. (2013) found that retrofitting an urban environment to intercept runoff through green areas is economical and protects the environment. Ellis and Lundy (2016) and Wang et al. (2017) discussed the use of SuDS to reduce stormwater flows within CSSs. SuDS encompass a diversity of drainage systems that can be grouped into four broad categories: storage systems (e.g. retention and detention ponds), infiltration systems (e.g. infiltration basins and soakaways),

Abbas, Alaa, I. Carnacina, F. Ruddock, R. Alkhaddar, G. Rothwell and R. Andoh. 2019 "An Innovative Method for Installing a Separate Sewer System in Narrow Streets." Journal of Water Management Modeling 27: C467. doi: 10.14796/JWMM.C467.

(c) CHI 2019. www.chijournal.org ISSN 2292-6062. 
conveyance systems (e.g. swales and filter strips) and permeable surfaces with storage. However, these approaches require large open areas, and their implementation is often met with many difficulties (Dhakal and Chevalier 2017).

The American Society of Civil Engineers conducted a study to separate the combined sewers for three cities in the United States by using a relatively small pressurized sanitary system to pump the sewage from houses and suspending it within the existing CSS, which had been previously used to convey only stormwater. Feasibility analysis for this project showed that the cost of the separation was more expensive than traditional SSSs due to the high initial cost of integrating new separate pressure systems into existing house units (Jones 2006). Many attempts have been reported to decrease the discharge from CSOs into the receiving watercourses by optimizing the sewerage networks through the implementation of a complex system that includes pressure pipes and additional storage tanks fitted with controller systems. This solution increases the storage capacities of sewer systems, but it is expensive to implement (Cembrano 2004; Polaskova et al. 2006).

Therefore, revisiting the traditional SSS with a new design that avoids the disadvantages of the old system can provide an optimum approach for installing SSSs in areas where space is lacking (Marvin and Slater 1997).

Accordingly, this paper discusses the application of an innovative design for an SSS that combines the two access chambers (the stormwater access chamber and the sanitary access chamber) into a single structure in a case study (Abbas, Alkhaddar et al. 2018). This combined structure has an innovative shape in that it allows sewage and stormwater to pass through it without becoming mixed, and it allows the two pipelines to be laid one over the other in one trench.

A combined inspection-access chamber (i.e. a single structure with two chambers, one for sewage and the other for stormwater) has been patented by a German company (Würmseher 2014); the shape proposed by the company was rectangular, and the storm pipe intersected the sanitary chamber to reach the storm chamber.

The Canadian Mortgage and Housing Corporation and the Canadian Water Network jointly sponsored a project intended to highlight successful innovative approaches to stormwater management across Canada. This project presented studies dealing with stormwater management at three levels or scales: the property level, neighbourhood level and watershed level. The researchers tried to increase storage capacity, pervious surfaces and retention time over these three levels by installing green roofs, using pervious pavements, building a stormwater pond, or using parking lots and creating wide riparian buffer zones (Marsalek and Schreier 2009). Planning and design criteria, construction and maintenance, performance evaluation, and the cost of innovative low impact development technologies have also been explored. This innovative system includes laying two perforated polyvinyl chloride pipes of $200 \mathrm{~mm}$ diameter below the original storm sewer system. They are connected to both the downstream and upstream access chambers below the storm sewers. This innovative solution is more economical than constructing a stormwater-quality pond to control the runoff from the site (Li et al. 2015).

\section{Materials and Methods}

We propose a new shape for a combined access chamber that is circular and avoids the intersection of pipes inside the chamber. Details of the chamber design and properties are discussed, and the application of this design in a case study is compared with a traditional sewerage design. Our novel design represents a solution for installing new SSSs or for separating existing CSSs in areas, such as cities in the United Kingdom and Europe and other dense cities around the world, where the space necessary for installing a traditional system is severely limited.

\subsection{Traditional Access Chamber}

The access chamber constitutes one of the main elements of a sewer network; it is used to gain access to the sewer for inspection and maintenance. Access chambers should be situated to provide easy access to the sewers. They should also be sited at every change in sewer alignment or gradient and wherever there is a change in the size of a sewer. They should be spaced at reasonable intervals, normally between $50 \mathrm{~m}$ and $100 \mathrm{~m}$, for inspection and maintenance (Hager 2010). Access chambers have witnessed many improvements over time in the materials used in their construction; old ones were built of brick, after which significant developments were made by using concrete and precast materials. However, the corrosion of concrete by $\mathrm{H}_{2} \mathrm{~S}$ forced the industry to either coat the inner surfaces of access chambers or use newly developed materials such as fibreglass and polyethylene (Hughes 2009). The typical design of a chamber is circular with a diameter between 1 $\mathrm{m}$ and $1.8 \mathrm{~m}$. Traditional SSSs normally have two separate access chambers, one for the stormwater flow and another for sewage. Figure 1 shows a typical cross section of the access chambers for an SSS in the street.

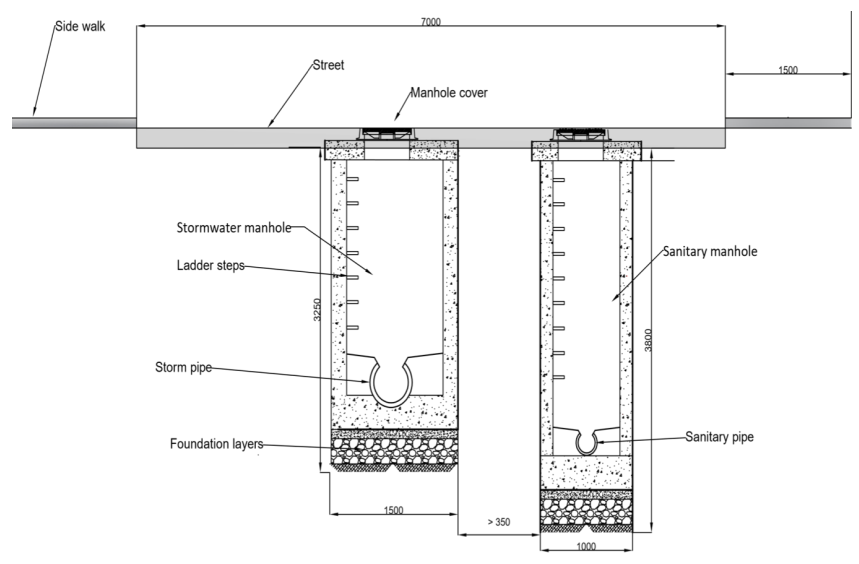

Figure 1 Typical section of a separate sewer system in the street showing the sanitary and storm access chambers (Al Ghalowa Afak project). 
The storm pipes and sanitary pipes of SSSs are typically installed either in separate trenches or in one large trench. The storm pipe and sanitary pipe are separated with a minimum horizontal distance of $35 \mathrm{~cm}$ to provide a comfortable working space during installation. Normally, the sanitary network is deeper than the storm network because the sanitary network should be situated at a lower elevation to receive flows from lateral pipes and prevent accidental spillovers from the sanitary network.

\subsubsection{Developing a Novel Access Chamber}

We present a novel design for the geometry of a chamber that integrates storm and sanitary access chambers into one combined structure while maintaining separate functions. The system is designed to ensure that the stormwater and sewage do not mix. The shape is cylindrical. It contains two coaxial chambers: the external chamber is used for stormwater sewer access and the internal chamber is used for sanitary sewer access. The elevation of the base of the storm chamber is at the same elevation as the bottom of the inlet storm pipe, while the base of the sanitary chamber extends to the same elevation as the bottom of the inlet sanitary pipe. Figure 2 provides details of the chamber design and the separation technique.

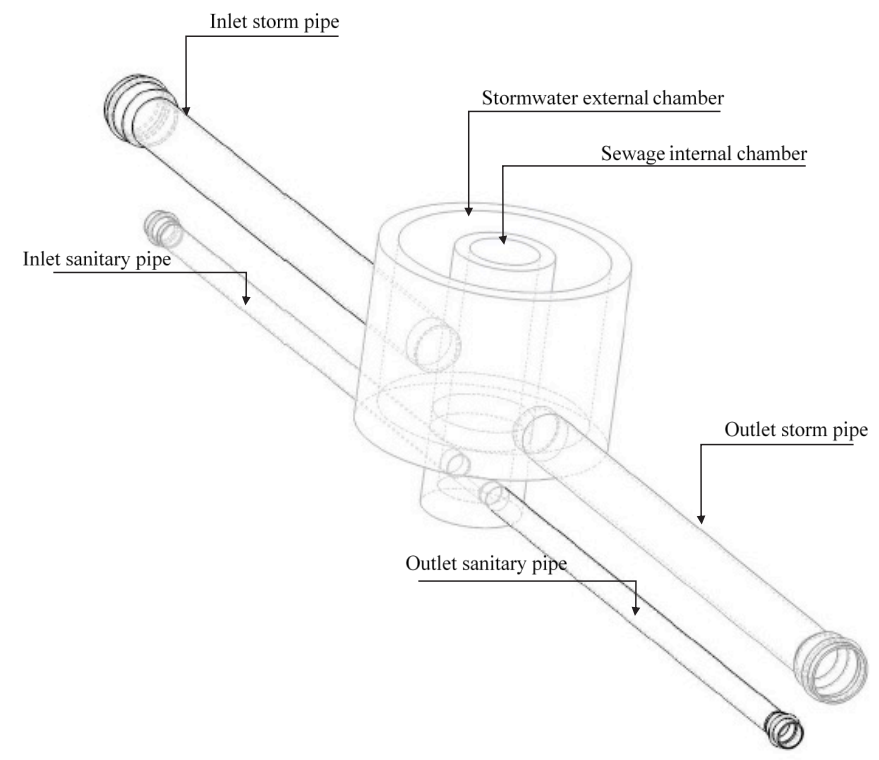

Figure 2 3D design of the innovative access chamber (Abbas, Alkhaddar et al. 2018).

The diameter of the internal chamber used for sewage flow can range from $0.7 \mathrm{~m}$ to $1 \mathrm{~m}$, while that of the external chamber used for storm flow can range from $2.1 \mathrm{~m}$ to $2.5 \mathrm{~m}$ depending on the design needs. In terms of BSEN476 (2011), these dimensions are appropriate for an inspection chamber, thereby allowing the equipment to enter with limited human access. The sanitary pipe extends below the sewer water chamber and terminates at the chamber, where it is connected normally as in a traditional system. The storm pipe terminates at the edges of the stormwater chamber; the flow follows a half circle around each side of the inner wall (the external wall of the sewage chamber) before arriving at the outer storm pipe (Abbas, Alkhaddar et al. 2018). Figure 3 illustrates a cross section of the proposed construction in the street.

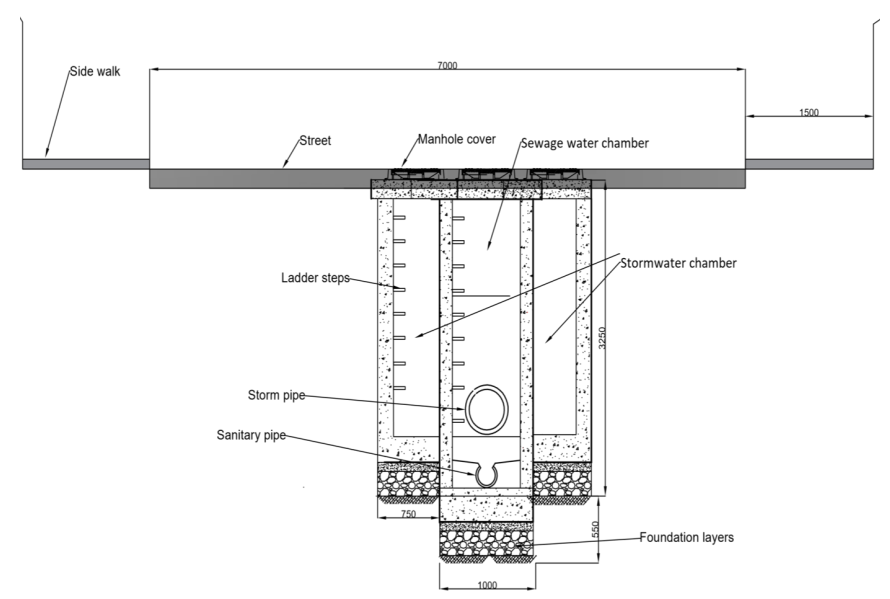

Figure 3 Cross section of the new access chamber located in the street for an SSS (Abbas, Ruddock et al. 2018).

The proposed design allows one trench to accommodate the two separate pipes with one above the other (i.e. the storm pipe on the top and the sanitary pipe on the bottom). A simple comparison between the two systems presented above shows immediately how the proposed layout of the chamber and pipes would reduce both the space required and the volume of excavated materials. A case study that was originally designed with a traditional SSS was selected for installation of the proposed design and evaluation of the advantages of the proposed system over a traditional system.

\subsection{Case Study}

A city from a developing country (Afak, Iraq) was selected to install the proposed design in one sector of the city in association with a study conducted by Al Ghalowa Co. Ltd., the company that designed the SSS in the city. The characteristics of Afak are listed in Table 1.

Table 1 The features of the case study site (Afak, Iraq).

\begin{tabular}{lc}
\hline \multicolumn{1}{c}{ Item } & Properties \\
\hline Population (capita) & 29228 \\
Area (ha) & 320 \\
& Average 116.84 \\
Annual precipitation $(\mathrm{mm})$ & Maximum 271.78 \\
Range of the street width $(\mathrm{m})$ & Minimum 45.72 \\
\hline
\end{tabular}

The client, the Afak Water Authority, required the design of a full SSS; however, the plan of the city, which is characterized by narrow streets already occupied by other infrastructure services, showed this task to be too challenging, and a partial SSS was developed instead. This study used the proposed access chamber design on the route of the partial SSS to explore the advantages of the new system over the traditional SSS wherever possible. 
This case study was chosen because the city plan shows narrow streets with widths $6.5 \mathrm{~m}$ and $8.5 \mathrm{~m}$. The proposed design would allow the installation of a full SSS, which conforms to the client's requirements, and it has the potential to be both effective and economically advantageous in other similar cases.

\section{Results and Discussion}

Theoretically, some of the partial SSS would be replaced using the proposed design. The routes of streets that included the two pipes of the traditional SSS were used to install the new system. Three parameters were used to identify differences between the proposed design and the traditional design: the initial construction costs, the footprint, and the hydraulic properties. The proposed design and the traditional system were compared in two steps. First, the design criteria and costs of both the new design and the traditional design were analysed. Second, the new design was used in the case study by replacing the SSS with the new system; the sanitary pipelines and storm pipelines were set in one street at elevations that are appropriate for use in the proposed system design.

\subsection{Cost Analysis}

Providing the funds to build and operate a separate drainage infrastructure constitutes one of the main barriers facing decision makers when implementing SSS (Starkl et al. 2009); therefore, reducing the initial construction costs can encourage planners to use the SSS. To evaluate the economic advantages of the sewer system design proposed in this research, two cost items have been considered:

1. The cost required to construct the new access chamber compared with the cost of constructing two chambers in a traditional system; and

2. The cost of laying two pipes in one trench compared with using two separate trenches as in a traditional system. The time factor also has an effect on the cost because sewer projects inevitably cause disturbances in the occupied areas, thereby affecting other community and business activities (Sousa et al. 2014).

\subsubsection{Access Chamber Construction Cost}

The criteria used to calculate the costs for the new access chamber and for the two chambers of the traditional SSS are listed in Table 2. To obtain these criteria, the diameters of the chambers in both systems were used to calculate the excavated and filling soil volumes, the quantities of concrete used to construct each chamber and the costs of the lids (covers). Table 2 shows that the cost of the new access chamber is approximately 1.25 times higher than the cost of both access chambers for a traditional SSS in the sub-main network (where the average chamber depth is $\sim 2.5 \mathrm{~m}$ ). This calculation conservatively assumed that the thickness of the internal wall used in the new system will be the same thickness as the wall used in a traditional sanitary access chamber. However, this thickness can be decreased significantly because no lateral load from the surrounding soil is applied to the internal chamber for the segment inside the external chamber. For example, if the thickness of the wall is reduced to half of the traditional wall thickness, the quantity of concrete can be reduced by approximately $3.5 \mathrm{~m}^{3}$, thereby decreasing the total cost by $\sim 1250$ USD. Moreover, other lightweight materials, such as glass-reinforced polyester, polyvinyl chloride (PVC) and high density plastic laminate, can be used for this internal segment wall. However, further research is needed to investigate the structural performance of the new chamber using either concrete walls or alternative materials.

Table 2 The unit costs, including materials and labour, used to calculate the total access chamber construction cost (data provided by the Afak Water Authority).

\begin{tabular}{|c|c|c|c|c|}
\hline Item & \multicolumn{2}{|c|}{$\begin{array}{l}\text { Innovative combined-sepa- } \\
\text { rate access chambers }\end{array}$} & $\begin{array}{c}\text { Traditional } \\
\text { storm access } \\
\text { chamber }\end{array}$ & $\begin{array}{l}\text { Traditional } \\
\text { sanitary ac- } \\
\text { cess chamber }\end{array}$ \\
\hline Diameter (m) & 2.5 & 1 & 1.5 & 1 \\
\hline Depth (m) & 2 & 2.5 & 2 & 2.5 \\
\hline $\begin{array}{l}\text { Quantity of excavation }\left(\mathrm{m}^{3}\right) \text {, includ- } \\
\text { ing } 0.3 \mathrm{~m} \text { around the manhole }\end{array}$ & 15 & 1 & 6.93 & 5 \\
\hline Quantity of concrete $\left(\mathrm{m}^{3}\right)$ & 17.9 & 8.65 & 10.78 & 8.65 \\
\hline Quantity of filling soil $\left(\mathrm{m}^{3}\right)$ & 5.275 & 0.6 & 3.4 & 3 \\
\hline Access covers (number) & 2 & 1 & 1 & 1 \\
\hline Estimated cost of unit (USD) & 8057 & 3387 & 5056 & 4073 \\
\hline Total cost (USD) & \multicolumn{2}{|c|}{11444} & \multicolumn{2}{|c|}{9129} \\
\hline
\end{tabular}

\subsubsection{Pipeline Installation Costs}

The calculation of the costs incurred to install the pipelines in this research included the earthwork and installation costs but excluded the cost of the pipe material because the same pipes were used in both systems. The factors that affect the pipe installation costs are the pipe diameter, the method of installation, the depth at which the pipes are buried, and the complexity of the site (Maurer et al. 2010). An open trench method, which is typically used to install sewer systems in the area of the case study, was used in this research. The construction plan for the original sewerage project of this case study was to set up the traditional SSS using two trenches, one for the sanitary pipe and one for the storm pipe. The trench for the sanitary pipe was excavated first; then, after installing the sanitary pipe, the trench was filled, and primary compaction was performed. Subsequently, a second trench was excavated for the storm pipe. This procedure was followed to avoid any collapses or damage to adjacent buildings on either side of the street in consideration of the street's narrow width. The hypothetical costs to install pipelines for the new system design included the earthwork of one trench with the same depth as that required to install the sanitary pipe in addition to the cost to install the storm pipe above the sanitary pipe within the same trench, which was laid at the bottom of the trench. The total cost ranged from $110 \%$ to $125 \%$ of the cost to install a traditional sanitary pipeline. 


\subsection{Using the New Design in the Case Study Area}

Specific areas in the case study were selected to upgrade the original design to the new system. The original design included sanitary (foul) networks designed for areas with a flat topography; therefore, five pumping stations were proposed in the original design to keep the cover depths of the pipes $<6 \mathrm{~m}$. The pipe diameters ranged from $0.25 \mathrm{~m}$ to $1.2 \mathrm{~m}$, and the access chamber diameters were between $1 \mathrm{~m}$ and $1.5 \mathrm{~m}$. A pipe with a diameter of $1.2 \mathrm{~m}$ was used to carry the sewage flow from the selected area and the flow from the extension area near the selected area to the treatment plant east of Afak downstream of the river. The stormwater network was laid out in the same areas as the sanitary network in the original design. The pipe diameters ranged from $0.315 \mathrm{~m}$ to $0.7 \mathrm{~m}$; these small diameters were selected because the stormwater network serves the selected area only over a short distance, and no flow originates in other connected areas (i.e. extension areas). Consequently, two pumping stations were located in the centres of the areas used to discharge storm flow to the natural open channel outside Afak.

The proposed design was used in the case study by replacing the traditional system where a storm pipe and a sanitary pipe were found in the same street and where the depths of the two systems allowed for the new system to be used. The new system required the elevation of the storm pipe to be above that of the sanitary pipe. Where the storm pipe was deeper than the sanitary pipe, the original design was not amended in the new design. The depths of the pipes selected for the installation of the new system ranged from $1 \mathrm{~m}$ to $2.5 \mathrm{~m}$. The diameter of the sanitary pipe was $0.25 \mathrm{~m}$, while the storm pipe diameters were from $0.315 \mathrm{~m}$ to $0.4 \mathrm{~m}$. The route of the new system configured with the original design is shown in Figure 4, in which the new pipelines and new access chambers are abbreviated as ComSepPipe and ComSep_Manhole, respectively.

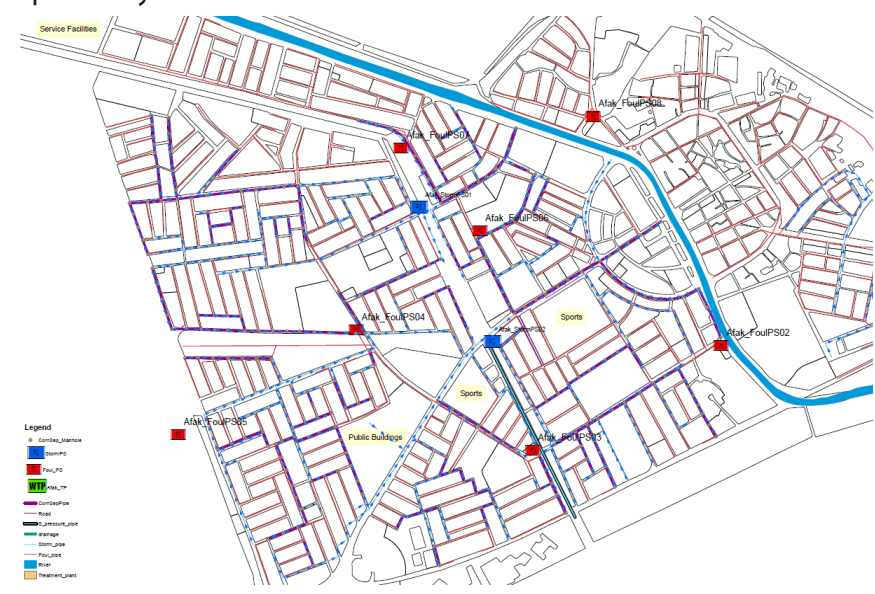

Figure 4 Configuration of the new design with the original design network to replace the traditional pipe system.
The pipe diameters and the slopes (i.e. hydraulic profiles) for both the sanitary networks and the storm networks were not changed in the new design; only the installation method was changed, from two open-cut trenches to one trench that accommodates both pipes. The total length of the new design route that replaced the traditional two-pipe system was $\sim 12595 \mathrm{~m}$ and 302 access chambers with the proposed design replacing nearly the same number of traditional access chambers (approximately 302 sanitary chambers and 308 storm chambers).

\subsubsection{Cost Comparisons}

The cost of installing the traditional system was calculated to compare it with the cost of installing the proposed system. The unit expenses used to calculate the costs of constructing the access chambers were provided by the Afak Water Authority. Table 3 shows the details of the calculated costs for the sanitary pipelines and storm pipelines in both the traditional system and the new system.

Table 3 Comparison of the costs (in USD) required to install the pipelines in both the traditional system and the proposed system within the case study area.

\begin{tabular}{lccc}
\hline Item & $\begin{array}{l}\text { Sanitary line in the } \\
\text { traditional system }\end{array}$ & $\begin{array}{c}\text { Storm line in the } \\
\text { traditional system }\end{array}$ & $\begin{array}{c}\text { Sanitary and storm } \\
\text { lines in new system }\end{array}$ \\
\hline $\begin{array}{l}\text { Estimated unit price of excavating } \\
\text { and laying pipe per meter }\end{array}$ & 100 & 100 & 115 \\
$\begin{array}{l}\text { Estimated unit price of constructing } \\
\text { access chamber }\end{array}$ & 4075 & 5050 & 11444 \\
$\begin{array}{l}\text { Total cost of lying a pipe } \\
\text { Total cost of constructing access }\end{array}$ & 1259500 & 1259500 & 1448425 \\
chambers & 1230650 & 1525100 & 3456088 \\
Total cost & 2490150 & 2784600 & 4904513 \\
Total compared cost & \multicolumn{2}{c}{5274750} & 4904513 \\
\hline
\end{tabular}

Comparison of the costs required to install the traditional pipeline system and those required to install the new system showed a $10 \%$ decrease in the cost relative to the former. This cost reduction could improve significantly if the initial construction costs of the new access chambers could be decreased further.

\subsubsection{Area Occupied by the System}

A sewer system has a larger footprint in the street compared with other infrastructure, such as potable water pipelines, electrical cables, communication cables or gas pipelines. Sewer systems also require larger pipe diameters and increased burial depths; therefore, when using the open cut method to install a sewer system, a large section of the street must be excavated (Riley and Wilson 2006). This larger footprint increases the risk that the installation of a sewer system will interfere with other utilities; for example, 75000 interference incidents occur every year in the United Kingdom (Read 2004).

The street footprints of the traditional sewer system and the new system are illustrated in Figure 1 and Figure 3. These figures show the average cross sections of the sewer systems along the route cover a distance of $12595 \mathrm{~m}$ in the case study used to 
simplify the calculation. Table 4 shows the criteria for the occupied area section and cost calculation.

Table 4 Criteria for calculating the cross section areas of the trenches and the volume of earthworks.

\begin{tabular}{|c|c|c|c|c|}
\hline \multirow{2}{*}{ Item } & \multicolumn{2}{|c|}{ Innovative SSS } & \multicolumn{2}{|c|}{ Traditional SSS } \\
\hline & Sanitary pipe & Storm pipe & Sanitary pipe & Storm pipe \\
\hline Average initial cover depth (m) & 2.5 & 2 & 2.5 & 2 \\
\hline Pipe diameter (m) & 0.315 & 0.25 & 0.25 & 0.315 \\
\hline Side slope of the trench $\left({ }^{\circ}\right)$ & \multicolumn{2}{|c|}{$60^{\circ}$} & $60^{\circ}$ & $60^{\circ}$ \\
\hline $\begin{array}{l}\text { Relationship between the trench width } \\
\text { (W) and pipe diameter (D) (m) }\end{array}$ & \multicolumn{2}{|c|}{$\mathrm{W}=3 \mathrm{D}$ (sanitary) } & $W=3 D$ & $W=3 D$ \\
\hline Trench width at street level (m) & \multicolumn{2}{|c|}{3.6} & \multicolumn{2}{|c|}{4.6} \\
\hline $\begin{array}{l}\text { Area of the cross section for the pipeline } \\
\text { excavation }\left(\mathrm{m}^{2}\right) \\
\text { Area of the cross section for the excav- }\end{array}$ & \multicolumn{2}{|c|}{4.35} & \multicolumn{2}{|c|}{7.125} \\
\hline $\begin{array}{l}\text { ation for manholes with supporting } \\
\text { side soil }\left(\mathrm{m}^{2}\right) \\
\text { Volume of earthworks for the pipe }\end{array}$ & \multicolumn{2}{|c|}{9.25} & \multicolumn{2}{|c|}{9.25} \\
\hline $\begin{array}{l}\text { cross section along the entire } 12595 \mathrm{~m} \\
\text { route }\left(\mathrm{m}^{3}\right)\end{array}$ & \multicolumn{2}{|c|}{54788} & \multicolumn{2}{|c|}{89739} \\
\hline
\end{tabular}

The cross sectional area of the proposed access chamber in the street was approximately $1.5 \mathrm{~m}^{2}$ less than that of the traditional chamber. Only the earthworks corresponding to the cross section of the pipe installation were considered. The calculation showed that the new system reduced the volume of earthworks by approximately $39 \%$.

The occupied area of the traditional system was calculated using the width of the trenches accommodating the two pipes, which was assumed to be three times the pipe diameter (BSEN752:2008 2013). The trench width is $\sim 1.7 \mathrm{~m}$ for both pipes in the traditional system, whereas the width $(0.94 \mathrm{~m})$ is three times the diameter of the larger pipe (the storm pipe) in the new system. This means that there is a $45 \%$ reduction in the area occupied by the pipelines when using the new system because only one trench is used to accommodate both pipes. The calculations for the access chamber cross sections given in Figures 1 and 3 show that the total width of the cross section of the traditional system is $3.7 \mathrm{~m}$, whereas that of the new system is $3.1 \mathrm{~m}$. Furthermore, the cross sectional area of the access chamber in the street is larger than the cross sectional area occupied by the pipeline system. Therefore, the area of the cross section occupied by the access chamber is considered only when calculating the space that can be given to other utilities along the path of the sewer pipeline. The difference is $\sim 0.6 \mathrm{~m}$, and the area along the path of the new system is reduced by $7557 \mathrm{~m}^{2}$, representing $16 \%$ of the area occupied by the traditional system. This reduction constitutes a considerable amount of space, especially in a narrow street, which can be allocated for other utilities.

\subsubsection{Construction Time}

The time factor in sewer projects, especially projects conducted in busy areas, is very important because it has social, environmental and economic consequences, all of which represent indirect costs of the installation of a sewer system. Some studies have created time-cost relationship models for sewer projects that include the impacts of sewer project activities on the community and business activities (Read and Vickridge 2004; Sousa et al. 2014). The reduction in the volume of earthworks is reflected in the total time saved over the project timeline. In the calculation of the project time, one crew was assumed to be working along the path of the new system compared with the traditional system, as presented in Table 5.

Table 5 Working times of one crew to install the pipelines in both the new system and the traditional system.

\begin{tabular}{lcc}
\hline \multicolumn{1}{c}{ Item } & Innovative SSS & Traditional SSS \\
\hline $\begin{array}{l}\text { Volume of earthworks for the pipe section along the entire } \\
12595 \mathrm{~m} \text { route }\left(\mathrm{m}^{3}\right)\end{array}$ & 54788 & 89739 \\
$\begin{array}{l}\text { Rate of excavation }\left(\mathrm{m}^{3} / \mathrm{d}\right) \\
\text { Estimated installation of pipelines, including filling with soil, }\end{array}$ & 120 & 120 \\
$\begin{array}{l}\text { compaction, and pipe installation }\left(\mathrm{h} / \mathrm{m}^{3}\right) \text {; data from the Afak } \\
\text { Water Authority for the traditional system and estimations by }\end{array}$ & 0.25 & 0.2 \\
the researchers for the new system & & \\
Total excavation time along the sewer route of the new system & 456 & 748 \\
Total installation time (d) with a workday consisting of $10 \mathrm{~h}$ & 1370 & 1795 \\
Total time (d) with one crew & 1826 & 3291 \\
\hline
\end{tabular}

The construction time is reduced by approximately $44 \%$ compared with the traditional system, which means that the installation of the proposed system is less of a nuisance to the community; in addition, there is a reduction in both indirect costs and environmental impacts resulting from occupying the sites and operating heavy machinery.

\subsection{Improved Integrity of Hydraulic Aspects}

\subsubsection{Storage Capacity}

Many studies have been conducted to enhance the hydraulic performance of sewer systems by increasing the system storage capacity as a solution to flooding problems (Polaskova et al. 2006; Cembrano 2004), whereas other studies have tried to increase retention times upstream of drainage networks (Andoh et al. 2005; Marsalek and Schreier 2009). Increasing the storage capacity of the system and the retention time for stormwater in the system will mitigate flooding risks downstream of the sewer system. The proposed access chamber design increases the area of the storm chamber by $\sim 2 \mathrm{~m}^{2}$ compared with that of the traditional storm sewer access chamber. The increase in the storage capacity volume depends on the manhole depth; for example, the average depth of the storm chamber and the traditional storm access chamber used in the case study was $\sim 2 \mathrm{~m}$. Table 6 shows the calculations of the storage capacity for both systems.

Table 6 Criteria for calculating the storage capacities for both the new system and the traditional system.

\begin{tabular}{lcc}
\hline \multicolumn{1}{c}{ Item } & $\begin{array}{c}\text { Innovative SSS } \\
\text { Storm }\end{array}$ & $\begin{array}{c}\text { Traditional SSS } \\
\text { Storm }\end{array}$ \\
\hline $\begin{array}{l}\text { Internal cross section area of the storm access chamber } \\
\left(\mathrm{m}^{2}\right)\end{array}$ & 3.8 & 1.3 \\
$\begin{array}{l}\text { Volume capacity of the chamber with a depth of } 2 \mathrm{~m} \\
\text { Total storage volume along the new design path (302 }\end{array}$ & 7.6 & 2.6 \\
access chambers) $\left(\mathrm{m}^{3}\right)$ & 2295 & 604 \\
\hline
\end{tabular}


The storage capacity of the storm network in the proposed system used in the case study increased by approximately $280 \%$ when compared with the storage capacity available for the storm network in the traditional system.

\subsubsection{Retention Time}

The new chamber shape extends the length of the flow path of stormwater through the storm chamber, as shown in Figure 5. These extended paths around the internal sanitary chamber increase the retention time for stormwater flowing inside the storm chamber, thereby enabling the system to absorb high-intensity rainfall. Table 7 shows a comparison of the retention time inside the storm chamber between the new system and the traditional system.

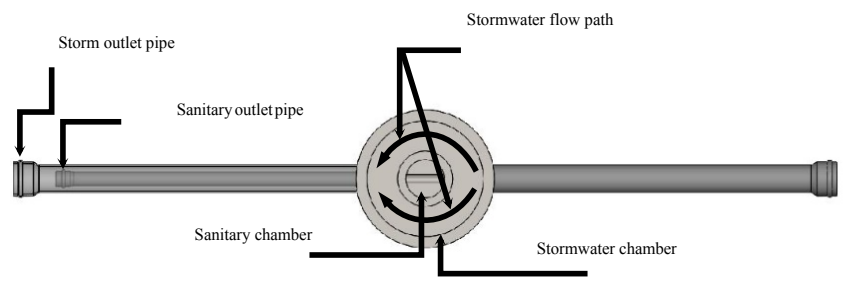

Figure 5 Top view of the new access chamber design showing the flow path of stormwater inside the storm sewer chamber.

Table 7 Comparison of the retention time between the new access chamber shape and the traditional storm sewer chamber.

\begin{tabular}{lcc}
\hline Item & $\begin{array}{c}\text { Innovative SSS } \\
\text { Storm }\end{array}$ & $\begin{array}{c}\text { Traditional SSS } \\
\text { Storm }\end{array}$ \\
\hline $\begin{array}{l}\text { Path of flow inside the storm manhole }(\mathrm{m}) \\
\text { Retention time inside the manhole, assuming a }\end{array}$ & 4.2 & 1.3 \\
$\begin{array}{l}\text { stormwater flow velocity of } 0.7 \mathrm{~m} / \mathrm{s}(\mathrm{s}) \\
\text { Total time along the new design path (302 access } \\
\text { chambers) (min) }\end{array}$ & 6 & 1.9 \\
\hline
\end{tabular}

The new system increased the retention time for the route selected in the case study by approximately $200 \%$. The storage capacity of the system and the retention time play significant roles in managing stormwater drainage and increasing the safety factor of the system against the risk of flooding.

\section{Conclusion}

Although SSSs are required by the most recent environmental regulations in many countries, the installation of a traditional SSS in narrow streets, which are common around the world, especially in the United Kingdom and Europe, is particularly challenging. We present an innovative design for an access chamber which combines the important advantages of the traditional SSS (fewer pollution effects on the watercourse) with those of the CSS (lower costs and smaller footprint). The new system possesses many economic and hydraulic advantages that have been tested by using the new system in a case study. The case study was designed using part of a traditional SSS. A comparison between the new system and the traditional sewer system showed that the new system decreases the initial costs by approximately $10 \%$ and reduces the construction time by $44 \%$. This reduction in the construction time can significantly reduce the indirect costs that result from the effects of the project on the community surrounding the site. Using the new system reduced the volume of earthworks by approximately $39 \%$ as a result of using one trench to accommodate the two separate pipes (the storm pipe and the sanitary pipe). The new system occupied less area than the area required by the traditional system by $\sim 16 \%$; salvaging this space can provide room for other utilities, especially in narrow streets. Moreover, the new system significantly improves the hydraulic integrity of storm networks; it increases the storage capacity by $280 \%$ compared with the traditional SSS and increases the retention time for stormwater flowing inside the storm network by $200 \%$ compared with the stormwater flow retention time of the traditional system.

\section{Acknowledgments}

The authors would like to acknowledge United Utilities Group PLC for providing technical support. The first author would like to acknowledge Al Ghalowa Co. Ltd. for supporting this study. Special acknowledgements are extended to the technician staff at LJMU for their assistance with the experimental setup.

\section{References}

Abbas, Alaa, Rafid Alkhaddar and Felicite Ruddock. 2018. “Manhole and Sewer Networks." In World Intellectual Property, edited by Liverpool John Moores University. UK.

Abbas, Alaa, Felicite Ruddock, Rafid Alkhaddar, Glynn Rothwell, and Robert Andoh. 2018. "Improving the Geometry of Manholes Designed for Separate Sewer Systems." Canadian Journal of Civil Engineering 46:13-25.

Andoh, R. Y. G., A. J. Stephenson and P. Collins. 2005. “Approaches to Urban Drainage Systems Management for the 21st Century." National Hydrology Seminar.

Astaraie-Imani, Maryam, Zoran Kapelan, Guangtao Fu and David Butler. 2012. "Assessing the Combined Effects of Urbanisation and Climate Change on the River Water Quality in an Integrated Urban Wastewater System in the UK." Journal of Environmental Management 112:1-9. https://doi.org/10.1016/j.jenvman.2012.06.039

Broere, Wout. 2016. "Urban Underground Space: Solving the Problems of Today's Cities." Tunnelling and Underground Space Technology 55:245-248. https://doi.org/10.1016/j.tust.2015.11.012

Brombach, H., G. Weiss and S. Fuchs. 2005. "A New Database on Urban Runoff Pollution: Comparison of Separate and Combined Sewer Systems." Water Science \& Technology 51 (2):119-28. 
BSEN476. 2011. General Requirements for Components Used in Drains and Sewers. London: BSI.

BSEN752:2008. 2013. Drain and Sewer Systems Outside Buildings. London: BSI.

Butler, D. and J. W. Davis. 2011. Urban Drainage. 3rd edn. London: Spon Press.

Cembrano, G. 2004. “Optimal Control of Urban Drainage Systems: A Case Study." Control Engineering Practice 12 (1):1-9. https://doi.org/10.1016/s0967-0661(02)00280-0

DEFRA. 2012. Waste Water Treatment in the United Kingdom. London Department for Environment, Food and Rural Affairs.

Dhakal, Krishna P. and Lizette R. Chevalier. 2017. “Managing Urban Stormwater for Urban Sustainability: Barriers and Policy Solutions for Green Infrastructure Application." Journal of Environmental Management 203:171-81. https://doi.org/10.1016/j.jenvman.2017.07.065

Ellis, J. Bryan and Lian Lundy. 2016. "Implementing Sustainable Drainage Systems for Urban Surface Water Management within the Regulatory Framework in England and Wales." Journal of Environmental Management 183:630-36. https://doi.org/10.1016/j.jenvman.2016.09.022

Ferreira, F., J. Matos, A. Galvão and M. A. Cardoso. 2011. “Assessing the Environmental Performance of Urban Wastewater Systems Using the INSA Model: Application to the Algés-Alcântara Wastewater System, in Portugal." Journal of Environmental Management 92 (11): 2944-52. https://doi.org/10.1016/j.jenvman.2011.07.007

Hager, W. H. 2010. Wastewater Hydraulics Theory and Practice. 2nd edn. Berlin: Springer.

Hughes, J. B. 2009. Manhole Inspection and Rehabilitation. 2nd edn. Reston, VA: American Society of Civil Engineers.

Jones, J. E. 2006. “ASCE Combined Sewer Separation Project Progress." In Great Works on Urban Water Resources (1962-2001), 73-88. Reston, VA: American Society of Civil Engineers. https://doi.org/10.1061/9780784408438

Li, James, Darko Joksimovic and John Tran. 2015. "A Right-of-Way Stormwater Low Impact Development Practice." Journal of Water Management Modeling 23: C390. doi: 10.14796/JWMM.C390.

Marsalek, Jiri and Hans Schreier. 2009. "Overview of the Theme Issue: Innovation in Stormwater Management in Canada: The Way Forward." Water Quality Research Journal of Canada 44 (1): 6.

Marvin, Simon, and Simon Slater. 1997. “Urban Infrastructure: The Contemporary Conflict Between Roads and Utilities." Progress in Planning 48 (4): 247-318. https://doi.org/10.1016/S0305-9006(97)00011-1
Maurer, M., M. Wolfram and H. Anja. 2010. "Factors Affecting Economies of Scale in Combined Sewer Systems." Water Science \& Technology 62 (1): 36-41.

https://doi.org/10.2166/wst.2010.241

Ouyang, Wei, Bobo Guo, Fanghua Hao, Haobo Huang, Junqi Li and Yongwei Gong. 2012. "Modeling Urban Storm Rainfall Runoff from Diverse Underlying Surfaces and Application for Control Design in Beijing." Journal of Environmental Management 113:467-73.

https://doi.org/10.1016/j.jenvman.2012.10.017

Polaskova, K., P. Hlavinek and R. Haloun. 2006. “Integrated Approach for Protection of an Urban Catchment Area." Desalination 188 (1-3): 51-9. https://doi.org/10.1016/j.desal.2005.04.101

Read, Geoffrey F. 2004. Sewers: Replacement and New Construction. Oxford: Elsevier/Butterworth-Heinemann.

Read, Geoffrey F. and lan Vickridge. 2004. "Social or Indirect Costs of Public Utility Works." In Sewers, edited by G. Read, 33966. Oxford: Elsevier/Butterworth-Heinemann.

Riley, Craig L. and Michael Wilson. 2006. Pipeline Separation Design and Installation Reference Guide. Olympia, WA: Washington State Department of Ecology and Washington State Department of Health.

Sousa, Vitor, Nuno Marques Almeida, Luís Alves Dias and Fernando António Branco. 2014. "Risk-Informed Time-Cost Relationship Models for Sanitation Projects." Journal of Construction Engineering and Management 140 (5). https://doi.org/10.1061/(asce)co.1943-7862.0000848

Starkl, Markus, Norbert Brunner, Werner Flogl and Johann Wimmer. 2009. "Design of an Institutional Decision-Making Process: The Case of Urban Water Management." Journal of Environmental Management 90 (2):1030. https://doi.org/10.1016/j.jenvman.2008.03.012

Wang, Mingming, Chris Sweetapple, Guangtao Fu, Raziyeh Farmani and David Butler. 2017. “A Framework to Support Decision Making in the Selection of Sustainable Drainage System Design Alternatives." Journal of Environmental Management 201:145-52. https://doi.org/10.1016/j.jenvman.2017.06.034

Wang, Ranran, Matthew J. Eckelman and Julie B. Zimmerman. 2013. “Consequential Environmental and Economic Life Cycle Assessment of Green and Gray Stormwater Infrastructures for Combined Sewer Systems." Environmental Science \& Technology 47 (19): 11189-98. https://doi.org/10.1021/es4026547

Würmseher, Hans. 2014. Abwasserschacht (Manhole). Berlin: Deutsches Patent-und Markenamt. 